\title{
Should Dopamine Agonists Be Given Early or Late? A Review of Nine Years Experience with Bromocriptine
}

\author{
Abraham N. Lieberman, Govindan Gopinathan, Hassan Hassouri, \\ Andreas Neophytides, and Menek Goldstein
}

\begin{abstract}
Experience with bromocriptine in 106 patients treated over nine years was reviewed. Most of the patients were already being treated with levodopa (combined with a peripheral decarbosylase inhibitor). These patients, after having initially achieved a good response to levodopa, were no longer responding satisfactorily. Most of the patients were also experiencing diurnal oscillations in performance: "wearing off" and "on-off" phenomena. In these patients previous attempts at changing the dose (increasing or decreasing) or changing the scheduling of levodopa had been unsuccessful. Bromocriptine was added to levodopa beginning at a dose of $5 \mathrm{mg} / \mathrm{day}$, and each week was increased by another $5 \mathrm{mg} / \mathrm{day}$. At a dose of bromocriptine of at least $25 \mathrm{mg} / \mathrm{day}$, there was a decrease in disability in the majority of patients with a decrease in the severity of the diurnal oscillations in performance (especially "wearing off" phenomena). In most patients, the addition of bromocriptine resulted in an approximately $10 \%$ reduction in the dose of levodopa. The majority of patients sustained their improvement at least one year. In some patients improvement was sustained for up to five years. The therapeutic efficacy of bromocriptine was limited in many patients by the occurrence of adverse effects including mental changes, dyskinesias, orthostatic hypotension, and nausea. These adverse effects could often be minimized by reducing the dose of bromocriptine or levodopa. All adverse effects were reversible upon stopping the drug. We have found bromocriptine to be a valuable adjunct in the treatment of these patients.
\end{abstract}

RÉSUMÉ: Nous revoyons notre experience avec la bromocriptine chez 106 patients sur une période de 9 ans. La plupart de ces patients reçevaient déjà la Lévodopa (avec un inhibiteur). La plupart aussi n'avait plus la réponse favorable du début. On notait également des oscillations diurnes dans la performance: "état de fin de dose" et "on-off". Des essais antérieurs de modification de dose ou de cédule n'avaient pas donné les résultats escomptés. La bromocriptine fut ajoutée à la Lévodopa à la dose initiale de 5 $\mathrm{mg}$ /jour, augmentée de façon hebdomadaire de $5 \mathrm{mg} /$ jour. A la dose d'au moins $25 \mathrm{mg} /$ jour on notait une diminution de l'atteinte chez la majorité des patients et une baisse dans la sévérité des oscillations diurnes (surtout de fin de dose). Chez la plupart des patients l'ajout de bromocriptine nécessitait une diminution de l'ordre de $10 \%$ de la dose de Lévodopa. Cette amélioration durait au moins un an, chez certains jusqu'à 5 ans. L'efficacité thérapeutique de la bromocriptine était souvent limitée par des efforts secondaires tels des changements mentaux, des dyskinésies, l'hypotension orthostatique et la nausée. On pouvait minimiser ces effets nocifs en réduisant la dose de bromocriptine ou de Lévodopa. Tous ces effets disparaissaient en cessant la médication. Chez ces patients la bromocriptine s'avère un adjoint utile.

Can. J. Neurol. Sci. 1984; 11:233-237

Bromocriptine has been established as a valuable adjunct in the treatment of Parkinson's disease, and it is instructive to reflect that skepticism greeted the initial report by Calne (Calne et al., 1978) and subsequent reports by others (Lieberman et al., 1976). Today, after nearly nine years of experience with the drug much has been learned, but there remain a number of questions. These include: Why is there such a range of therapeutic responses (from marked to none)? Why does the therapeutic efficacy of bromocriptine decline? Should bromocriptine be used as the initial treatment for Parkinson's disease? Is bromocriptine useful for patients with diurnal oscillations in performance, "wearing off" and "on-off' phenomena? Is bromocriptine effective in low doses (less than $15 \mathrm{mg} /$ day)?

\section{Methods}

We reviewed our experience with bromocriptine in seven published papers, which included 106 patients. We began using bromocriptine in 1974, after studies in our animal models of Parkinson's disease (rats with unilateral nigrostriatal lesions and monkeys with ventral mesencephalic lesions) convinced us of bromocriptine's effectiveness (Goldstein et al., 1979). The first five papers are prospective studies that deal with bromocriptine's general efficacy (Lieberman et al., 1976a, b: 1979a; $1980 \mathrm{a}, \mathrm{b})$.

The last two papers are retrospective studies that deal with bromocriptine's efficacy in patients with diurnal oscillations in performance (Lieberman et al., 1979a; 1983). Patients from one study frequently participated in another study. At present, we have treated 300 patients with bromocriptine.

In our first study, 11 patients with Parkinson's disease participated (Lieberman, et al., 1976a). All of these patients had been on levodopa (alone or combined with a peripheral decarboxylase inhibitor). Nine of these patients had initially

From The Department of Neurology, New York, University School of Medicine, New York

Reprint requests to: Dr. Abraham N. Lieberman, 530 First Avenue, N.B. 7W15, New York, New York 10016 U.S.A. 
improved on levodopa, but, at the time of the study, their response had plateaued. Ten patients continued on levodopa during the study. Bromocriptine was begun at $5 \mathrm{mg} /$ day, and was increased by $5 \mathrm{mg} /$ day every week. Because of limited experience at this time with bromocriptine, the dose did not exceed $30 \mathrm{mg} /$ day.

In the second study, 14 patients participated (Lieberman et al., 1976b). In this study an attempt was made to discontinue levodopa in as many of the 14 patients as possible so that the efficacy of bromocriptine could be compared with that of levodopa. In this study, as in the subsequent studies, all of the patients had been treated with levodopa. Most of them had initially responded to levodopa, improving at least one stage. However, most of the patients were now becoming increasingly disabled, and many were even worse than they had been at the time they started levodopa. Most of the patients exhibited diurnal oscillations in performance. In our patients attempts to increase levodopa resulted in adverse effects indicative of central dopamine excess, dyskinesias and mental changes. Attempts to decrease levodopa resulted in worsening of the patients' disability. Levodopa drug "holiday" of 3 to 14 days' duration, changes in the frequency of levodopa administration, and changes in the ratio of levodopa to inhibitor were only temporarily helpful. The dose of bromocriptine was begun at $5 \mathrm{mg} /$ day and was increased by 5 to $10 \mathrm{mg} /$ day each week until adverse effects occurred (mental changes, dyskinesias, orthostatic hypotension, nausea), at which point the dose of levodopa was reduced. Other anti-Parkinson medications were unchanged. Patients were examined at regular intervals by a neurologist who was unaware of what medications the patients were receiving. The neurologist assessed the cardinal signs of the disease: rigidity, tremor, bradykinesia, postural stability and gait disorder on a standardized examination in which " 0 " represents no disability and "100\%" maxima! disability (Lieberman, et al., 1980c). Patients were also staged on the Hoehn and Yahr Scale. For this review, the results of all of the studies were reported on the Hoehn and Yahr Scale with the exception of the study comparing bromocriptine (alone) to levodopa. Dyskinesias were separately assessed. Statistical analyses were performed using the matchedpair $\mathrm{T}$ test at the 5\% level of significance. Diurnal oscillations in performance were evaluated by examining patients when they were in "on" and "off" periods, by asking patients to keep a daily $\log$ of their "on" and "off" periods and to report the number of hours they were "on". These logs were periodically verified by a neurologist.

In the third study, 66 patients were treated with bromocriptine in addition to levodopa (Lieberman, et al., 1979a). These patients included the 25 previously reported. In the fourth study, 106 patients were treated with bromocriptine in addition tolevodopa (Lieberman, et al., 1980a). This study included the patients previously reported. All 66 patients had been treated with amantadine or an anticholinergic agent, and 40 were still receiving these drugs. Eleven of the patients had dementia. In the fifth study, we evaluated 28 of the 106 patients who had been treated with bromocriptine for at least two years (Lieberman, et al., 1980b).

To evaluate the efficacy of bromocriptine in patients with diurnal oscillations in performance, we examined the data from two retrospective studies which specifically looked at these oscillations. In the first of the studies, the efficacy of bromocriptine was compared to lergotrile (another dopamine agonist) in 20 patients (Lieberman et al., 1979b). In the second study, bromocriptine was compared to pergolide (another agonist) in 25 patients (Lieberman et al., 1983). In addition, the data from study four including 51 patients and study five including 21 patients with diurnal oscillations were also examined.

The long term efficacy of bromocriptine was evaluated in each of the five prospective studies.

\section{RESUlts}

Results of these studies on the efficacy of bromocriptine are presented in Tables 1-4. Table 1 documents the age range of patients, the duration of Parkinson's disease, the dose of levodopacarbidopa, and duration of treatment for each of the five studies which are reviewed. Also presented are the number of patients in each study with dementia or diurnal oscillations in performance.

The effect of prior treatment with levodopa is summarized in Table 2. This shows the clinical stage of the patient (Hoehn and Yahr scale) before starting levodopa and also at the time of peak effect following administration of levodopa. Figures are given to indicate the number of patients who improved by at

Table 1: Pretreatment Data in Patients Receiving Bromocriptine for Parkinson's Disease

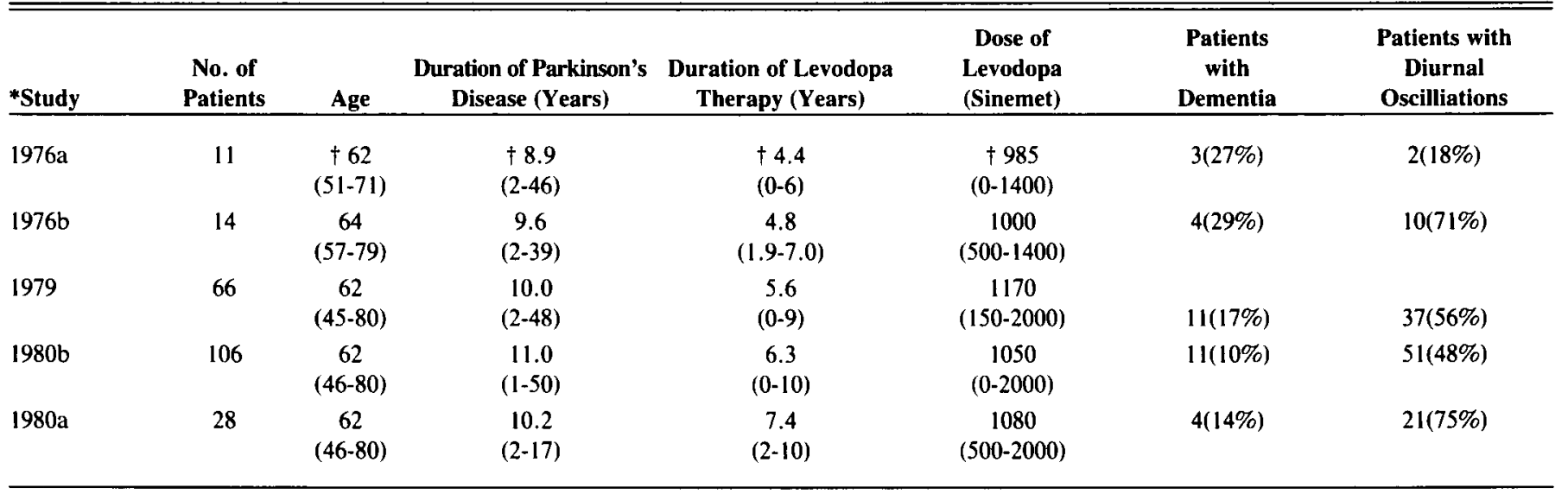

\footnotetext{
* See references to Lieberman et al.

$\dagger$ Mean values (figures in brackets indicate range).
} 
Table 2: Bromocriptine in Parkinson's Disease - Prior Levodopa Treatment

\begin{tabular}{|c|c|c|c|c|c|c|c|}
\hline Study & $\begin{array}{c}\text { No. of } \\
\text { Patients }\end{array}$ & $\begin{array}{c}\text { Stage Before } \\
\text { Levodopa }\end{array}$ & $\begin{array}{c}\text { Stage at Peak } \\
\text { of Levodopa }\end{array}$ & $\begin{array}{l}\text { No. Improving } \\
\text { More Than I Stage }\end{array}$ & $\begin{array}{c}\text { Stage Before } \\
\text { Bromocriptine }\end{array}$ & $\begin{array}{l}\text { No. Improving } \\
\text { More Than } 1 \text { Stage }\end{array}$ & $\begin{array}{c}\text { No. Worsening } \\
\text { More Than I Stage }\end{array}$ \\
\hline $1976 \mathrm{~b}$ & 14 & $2.6(2-4)$ & $2.0(0-4)$ & 6 & $3.6(1-5)$ & 1 & 10 \\
\hline 1979 & 66 & $2.7(2-4)$ & $1.6(0-3)$ & 48 & $3.7(2-5)$ & 3 & 44 \\
\hline $1980 \mathrm{~b}$ & 106 & $2.8(2-5)$ & $1.8(0-4)$ & 65 & $3.3(2-5)$ & 14 & 56 \\
\hline
\end{tabular}

* Mean Values. Figures in brackets indicate range.

\begin{tabular}{lccccc}
\hline Table 3: Results of Treatment With Bromocriptine in Parkinson's Disease & & \\
\hline \hline & & $\begin{array}{c}\text { Dose of } \\
\text { No. of Patients }\end{array}$ & $\begin{array}{c}\text { Stage Before } \\
\text { Treatment }\end{array}$ & $\begin{array}{c}\text { Stage at Peak } \\
\text { of Bromocriptine }\end{array}$ & $\begin{array}{c}\text { No. Improving } \\
\text { More than 1 Stage }\end{array}$ \\
\hline $1976 \mathrm{a}$ & 11 & $126(15-50)$ & $3.3 \pm 0.3^{2}$ & $* 2.5 \pm 0.3$ & $6(36 \%)$ \\
$1976 \mathrm{~b}$ & 14 & $57(25-100)$ & $3.6 \pm 0.2$ & $* 2.8 \pm 0.2$ & \\
1979 & 66 & $47(25-100)$ & $3.2 \pm 0.2$ & $* 2.5 \pm 0.1$ & $25(39 \%)$ \\
$1980 \mathrm{~b}$ & 106 & $41(5-100)$ & $3.2 \pm 0.1$ & $* 2.7 \pm 0.1$ & $55(52 \%)$ \\
$1980 \mathrm{a}$ & 28 & $56(30-100)$ & $3.0 \pm 0.1$ & $* 2.0 \pm 0.2$ & $21(75 \%)$ \\
\hline
\end{tabular}

\footnotetext{
' Mean Values (Figures in brackets indicate range)

${ }^{2}$ Standard Error of Mean

* $\mathrm{P} \leqslant 0.1$ to 0.5
}

\begin{tabular}{lcccccccc}
\hline \multicolumn{2}{l}{ Table 4: Effect of Bromocriptine on Diurnal Oscillations in Performance. Values Shown Represent Mean Scores } \\
\hline \hline
\end{tabular}

$* \mathrm{P} \leqslant .01$ to .05

least one clinical stage. Also documented in Table 2 are data summarizing the clinical stages for these same groups of patients prior to starting bromocriptine, and the number of patients who improved or worsened following treatment with bromocriptine.

Table 3 further summarizes the results of treatment with bromocriptine. It shows the mean dose and range of dosages used in each of the five studies and the clinical stages of the patients before and during treatment. Significant improvement in the mean clinical scores occurred in all the studies.

The results of bromocriptine therapy in patients with diurnal oscillations in performance are shown in Table 4. It can be seen that, although fluctuations continue to occur, clinical scores were improved in both the "on" period and "off" periods following bromocriptine. In two of the studies, the number of hours per day in which the patients were in an "on" state was documented before and after starting bromocriptine.
Treatment with bromocriptine alone is compared with levodopa in Table 5. This shows the clinical score and stages of patients on levodopa and also while they were receiving bromocriptine alone. Also listed are the doses of levodopa or bromocriptine which were used. Although there were no differences between the scores and stages when they were on levodopa and the values obtained when they were on bromocriptine, the patients could not be maintained on bromocriptine alone and eventually (within several weeks) were changed to a combination of bromocriptine and levodopa. Data on the long term efficacy of bromocriptine are listed in Table 6 and include: the number of patients in each of the studies, the mean dose of bromocriptine, the per cent decrease in the dose of levodopa, the duration of treatment with bromocriptine, and the number of patients who initially improved at least one stage on bromocriptine, and the number (and per cent) of patients who were able to maintain 
Table 5: Results of Treatment with Bromocriptine Alone Versus Levodopa in 7 Patients

\begin{tabular}{lc}
\hline Age of patients (mean/range) & 65 years $(60-75)$ \\
Duration of Parkinson's Disease & 4.7 years (2-7) \\
Levodopa & \\
$\quad$ Average daily dose & $1250 \mathrm{mg}$. \\
$\quad$ Clinical score & $3.6 \pm 0.2$ (SEM) \\
$\quad$ Hoehn and Yahr stage & $54 \pm 4.9$ \\
$\quad$ NYU Scale & \\
Bromocriptine & $70 \mathrm{mg}$. \\
Average daily dose & \\
Clinical score & $3.6 \pm 0.2$ \\
$\quad$ Hoehn and Yahr stage & $45 \pm 4.1$ \\
NYU Scale &
\end{tabular}

this improvement. Initially, between $36 \%$ and $75 \%$ of patients improved at least one stage when bromocriptine was added to levodopa, but only $18 \%$ to $43 \%$ of the patients maintained their improvement. In the longest study (Lieberman et al., 1980a), the mean duration of bromocriptine treatment was 2.3 years, and the largest per cent of patients $(74 \%)$ showed initial improvement. The patients in this study who were on bromocriptine the longest were those who also derived the most benefit from it. However, after a mean of 2.3 years (range 2-5 years) only $18 \%$ of these patients maintain their improvement. The adverse effects of bromocriptine which lead to its discontinuation are listed in Table 7.

\section{Discussion}

Bromocriptine's efficacy is most clearly demonstrated in studies of naive (untreated) patients whose clinical improvement is due only to bromocriptine (Lees et al., 1978). On bromocriptine alone, such naive patients do not develop dyskinesias or diurnal oscillations in performance. This observation has been cited as justification for starting bromocriptine as soon as possible in all patients including those already on levodopa. It is believed by many neurologists that by starting bromocriptine early, the dose of levodopa can be kept low and thus delay the onset of dyskinesias and diurnal oscillations in performance, adverse effects that are believed by many neurologists to result from the cumulative effects of chronic levodopa treatment itself. It is believed that these adverse effects may be minimized by keeping the dose of levodopa as low as possible for as long as possible. We were able to demonstrate a somewhat comparable effect in seven patients in whom levodopa was discontinued and bromocriptine was substituted for it (Lieberman et al., 1976b). However, we (and others) found that treatment with bromocriptine alone could not be sustained, and levodopa had to be added.

We, and others, have found bromocriptine most useful in patients whose response to levodopa has diminished, and in whom attempts to increase or decrease the dose of levodopa were unsuccessful. In these patients, including those who suffer form diurnal oscillations in performance (especially patients with "wearing off" phenomena), the addition of bromocriptine to levodopa usually results in a decrease in disability either in their "on" or their "off" periods or both, and increases the number of hours they are "on". Additionally, many patients report improvement in specific target symptoms that occur with varying degrees of severity in most patients. In some patients, the target symptoms are so distressing that alleviation of one or more of them has a dramatic effect. Examples of these target symptoms are disturbances of the following functions: ability to turn in bed, arise from a chair, initiated gait, turn and pivot while walking, speak loudly or distinctly (especially over

Table 6: Bromocriptine in Parkinson's Disease: Long Term Efficacy

\begin{tabular}{|c|c|c|c|c|c|}
\hline $\begin{array}{c}\text { No. of } \\
\text { Patients }\end{array}$ & $\begin{array}{l}\text { Mean Dose } \\
\text { of BC ( } \mathbf{m g})\end{array}$ & $\begin{array}{c}\text { \% Change in } \\
\text { Levodopa Dose }\end{array}$ & $\begin{array}{c}\text { Mean Duration of } \\
\text { BC Therapy (Years) }\end{array}$ & $\begin{array}{c}\text { Patients with } \\
\text { Initial Improvement } \\
\text { More Than } 1 \text { Stage }\end{array}$ & $\begin{array}{c}\text { Maintained } \\
\text { Improvement } \\
\text { More Than 1 Stage }\end{array}$ \\
\hline 11 & 26 & 0 & 0.5 & $4(36 \%)$ & $2(18 \%)$ \\
\hline 14 & 57 & $-31 \%$ & 0.5 & $10(71 \%)$ & $6(43 \%)$ \\
\hline 66 & 47 & $-10 \%$ & $\begin{array}{c}0.6 \\
(0.2-2.0)\end{array}$ & $25(39 \%)$ & $21(32 \%)$ \\
\hline 28 & 56 & $-21 \%$ & $\begin{array}{c}2.3 \\
(2.0-5.0)\end{array}$ & $21(75 \%)$ & $5(18 \%)$ \\
\hline
\end{tabular}

Table 7: Adverse Effects Necessitating Discontinuation of Bromocriptine in 54 of 106 Patients (From Lieberman et al. 1980a)

\begin{tabular}{lc} 
Adverse Effect & $\begin{array}{c}\text { Number } \\
\text { Of Patients }\end{array}$ \\
\hline Mental changes & 29 \\
Dyskinesias & 11 \\
Orthostatic hypotension & 9 \\
Nausea & 4 \\
Edema & 1 \\
\hline
\end{tabular}

the telephone), and write clearly. Other target symptoms are freezing, falling and drooling. While bromocriptine does not abolish all of the diurnal oscillations in performance nor reverse all of the target symptoms, the results in most patients are sufficiently gratifying to justify using the drug.

The duration of bromocriptine's efficacy varies. In one group of patients, efficacy was maintained for up to five years (Lieberman et al., 1980a). However, in some patients, bromocriptine's efficacy began to decline within one year. In general, the response to bromocriptine declined more rapidly in patients with advanced disease on high doses of bromocriptine. 
Several reasons have been advanced to explain why bromocriptine does not work in all patients, and why its efficacy declines. It is conceivable that bromocriptine acts through one of its metabolites, that the metabolism of bromocriptine differs in the individual patients, and that some metabolites are more active as anti-parkinsonian agents than others. Additionally, it is possible that, in individual patients, there is a change in the metabolism of bromocriptine over time which may account for the decline in efficacy. (2) Bromocriptine works both through pre- and post-synaptic mechanisms, and has the properties of being both an agonist and an antagonist. Some of these mechanisms are contradictory, i.e., some of them promote bromocriptine's anti-parkinsonian effect, and some negate it (Goldstein, et al., 1979). (3) The number of available postsynaptic striatal dopamine receptors eventually decreases, and this may account for the decrease in efficacy.

A number of adverse mental changes have been reported with bromocriptine. Some of these, such as hallucinations, delusions, agitation, and confusion, may be related to the drug and disappear when it is stopped; others such as memory loss, may be related to the dementia that occurs in a third of patients with Parkinson`s Disease (Lieberman, et al., 1979c). In general, it is unadvisable to use bromocriptine in a patient with obvious dementia. Other adverse symptoms include dyskinesias, cramps, orthostatic hypotension, dependent edema, nausea and vomiting. One group, in an attempt to reduce the incidence of adverse effects and increase the number of patients who can tolerate bromocriptine started the drug at a low dose $(1 \mathrm{mg} /$ day) and increased it slowly at a rate of no more than $1 \mathrm{mg} /$ day each week (Teychenne, et al., 1982). It was reported that several patients improved on as little as 3 or $4 \mathrm{mg} /$ day of bromocriptine. While we have noted improvement in some patients on as little at 15 $\mathrm{mg} /$ day, it is difficult for us to document improvement on lower doses.

\section{REFERENCES}

Calne DB, Williams AC. Neophytides A, (1978) Long term treatment of parkinsonism with bromocriptine. Lancet i:735-378.

Goldstein M. Lew JY, Engle J. (1979) Dopaminergic ergot derivatives and motor funciton. Fuxe K. Calne DB (Editors). Pergamen Press. Oxford, pp. 235-260.

Lees AJ, Haddad S, Shaw KM, (1978) Bromocriptine in parkinsonism. Arch. Neurol. 35:503-505.

Lieberman A, Zolfaghari M. Boal D, (1976a) The anti-parkinsonian efficacy of bromocriptine. Neurology 26:405-409.

Lieberman A, Kupersmith M. Estey E, Goldstein M. (1976b) Treatment of Parkinson's disease with bromocriptine. New Engl. J. Med. 295:1400-1404.

Lieberman AN, Kupersmith M, Gopinathan G. (1979a) Bromocriptine in Parkinson's disease: further studies. Neurology 29:363-369.

Lieberman AN, Kupersmith M. Gopinathan G. (1979b) Modification of the "on-off" effect with bromocriptine and lergotrile. In Dopaminergic Ergot derivatives and motor function. Fuxe K. Calne DB (Editors). Pergamen Press, Oxford \& New York. pp. 285-295.

Lieberman A, Dziatolowski M, Kupersmith M. (1979c) Dementia in Parkinson's disease. Ann. Neurol. 6:355-359.

Lieberman A, Kupersmith M. Neophytides A, (1980a) Long term efficacy of bromocriptine in Parkinson's disease. Neurology $30: 518-523$.

Lieberman AN, Kupersmith M. Neophytides A, (1980b) Bromocriptine in Parkinson's disease: report on 106 patients treated for up to five years. In Ergot Compounds and Brain Function: Neuroendocrine and Neuropsychiatric Aspects. Goldstein M. et al. (Editors) Raven Press, New York, pp. 245-253.

Lieberman A. Dziatolowski M. Gopinathan G. (1980c) Evaluation of Neuroendocrine and Neuropsychiatric Aspects. Goldstein M. et al. (Editors) Raven Press, New York, pp. 277-286.

Lieberman AN, Neophytides A. Leibowitz M. (1983) Comparative efficacy of pergolide and bromocriptine in patients with advanced Parkinson's disease. Adv. in Neurol. 37:95-108.

Schran HF, Bhuta SI, Schwarz HJ. Thorner MO. (1980) The pharmacokinetics of bromocriptine in man. In Ergot Compounds and Brain Function: Neuroendocrine and Neuropsychiatric Aspects. Goldstein $M$ et al. (Editors) Raven Press, New York. pp. 125-139.

Teychenne, PF, Berg S, Rud D, Ray A. (1982) Bromocriptine: low dose therapy in Parkinson's disease. Neurology 32:577-583. 